\title{
'ADULT PATTERN' OF PULMONARY VESSELS IN NEWBORN INFANTS
}

\author{
BY \\ M. A. THOMAS \\ From the Department of Pathology, University of Singapore, Singapore
}

(RECEIVED FOR PUBLICATION OCTOBER 14, 1963)

The study of pulmonary vessels has assumed great importance in the last decade since the advent of corrective surgery for congenital cardiac defects. Several papers have been written on the structure and state of these vessels, in utero, in neonatal life and during later years (Edwards, 1957; Civin and Edwards, 1951; Dammann and Ferencz, 1956a). These papers stress the basic differences in the pulmonary vessels during these different periods.

The vessels showing the most striking differences between intrauterine and other periods of life are the small muscular arteries and arterioles. These vessels in the foetus have thick walls with narrow lumina (Figs. 1 and 2), thus producing high pulmonary vascular resistance (Civin and Edwards, 1951; Edwards, 1957): the lumen-to-wall ratio of these vessels in the foetus is $1: 1$. The narrow lumen is thought to be due partly to vasoconstriction and partly to the presence of thick muscular media in these vessels (Edwards, 1957). This arrangement is most advantageous during intrauterine life, when most of the blood from the right ventricle is to be diverted to the systemic circulation through the ductus arteriosus, since the lungs have no aerating function (Barclay, Franklin and Prichard, 1944; Lind and Wegelius, 1949). After birth, however, all the right ventricular blood must be shunted through the lungs. To enable this to happen the pulmonary vessels dilate, their walls become thin and the lumen becomes wide. The media of the small muscular artery becomes thin, and the media of the arteriole almost completely disappears, and the lumina of these vessels become much larger than the wall, the lumen-to-wall ratio finally reaching the adult

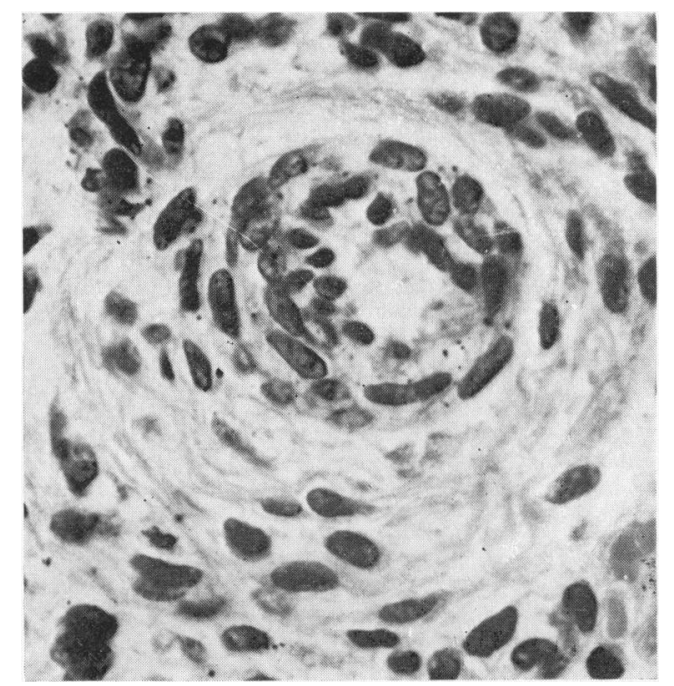

FIG. 1.-Small muscular artery-foetal type with thick muscular media and narrow lumen (Haematoxylin and eosin. $\times 500$ ).

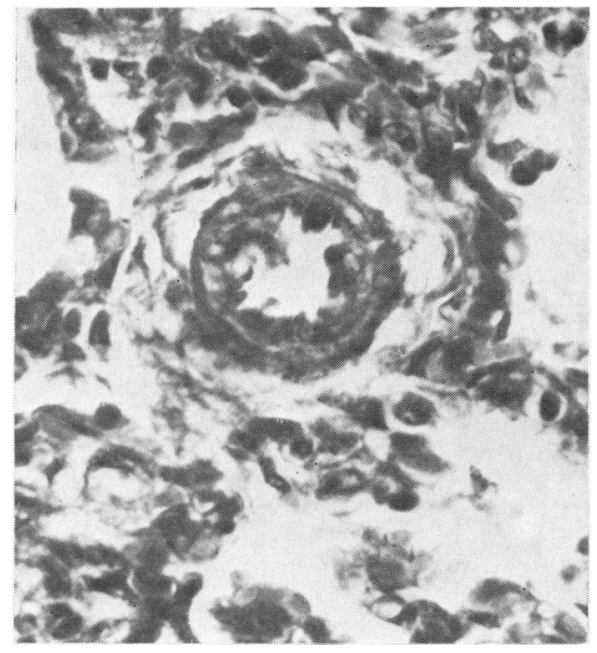

FIG. 2.-Arteriole-foetal type with muscular media and narrow lumen (Verhoeff-van Gieson. $\times 500$ ). 
pattern of $10: 1$ (Edwards, 1957; Goodale and Thomas, 1954). This changeover from the foetal to the adult pattern is gradual; in the first few days of life the lumen-to-wall ratio becomes $2 \cdot 3: 1$, and the adult pattern is established between the sixth and twelfth months of life (Heath, Swan, DuShane and Edwards, 1958).

Persistence of the foetal pattern of pulmonary vessels gives rise to primary pulmonary hypertension when not associated with any congenital cardiac defects. When the foetal pattern persists in association with a cardiac defect, it is said to give rise to secondary pulmonary hypertension (Dammann and Ferencz, 1956a; Edwards, 1950; Edwards, Douglas, Burchell and Christensen, 1949; Dammann and Muller, 1953).

Premature dilatation of the pulmonary vessels occurring in the first few days of life in infants with and without major cardiac defects has been described only once previously (Heath et al., 1958).

The present paper deals with the premature establishment of adult pattern of pulmonary vessels and its attendant clinical complications occurring in newborn infants, some of them with major cardiac defects and some with only a small patent ductus arteriosus which is often present.

\section{Material and Methods}

The pulmonary vasculature of 700 consecutive newborn and stillborn infants dying from diverse causes was studied at necropsy. The age of the live-born infants varied from a few hours to 5 days. These necropsies were done at the Kandang Kerbau Hospital, Singapore. The lungs were fixed in $10 \%$ formol-calcium, and a minimum of six sections was taken from each case, one from each lobe and one from the lingula. The sections were stained with haematoxylin and eosin and Verhoeffvan Gieson. The vessels were identified using Brenner's (1935) and Edwards' (1957) criteria. Special attention was paid to the small muscular arteries and arterioles. The width of the lumen and the vessel wall was measured in 100 vessels (small muscular arteries and arterioles) in each case and the average lumen-to-wall ratio was recorded. In addition to the histological examination of the lungs, the hearts were examined for the presence of congenital cardiac defects, for thickness and for dilatation of the ventricles.

\section{Results}

In 693 cases, i.e. an overwhelming majority, the pulmonary vasculature was of the foetal and the neonatal type, the lumen-to-wall ratio varying from $1: 1$ to $3: 1$. The arterioles had thick media. The lumen-to-wall ratio varied with the age of the infant (Table 1). In the remaining 7 cases histological examination showed the pulmonary vasculature to be predominantly of the 'adult' type. Over $90 \%$ of the vessels examined showed widely dilated vessels with thin walls (Figs. 3 and 4). The arterioles had very thin media and the lumen-to-wall ratio varied from $7: 1$ to $8: 1$. All these cases showed severe pulmonary oedema and congestion histologically.

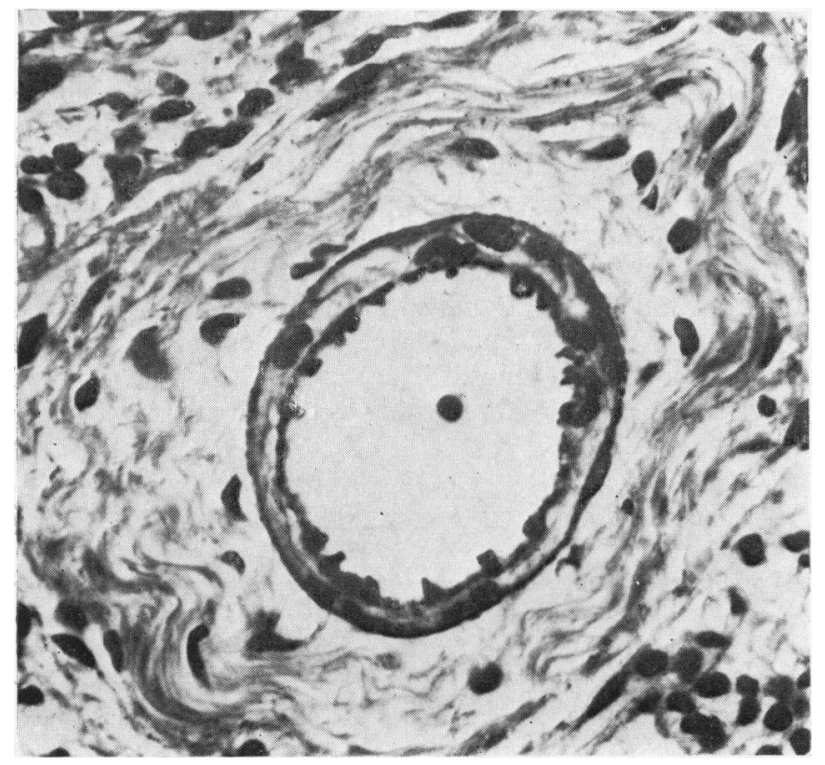

FIG. 3.-Small muscular artery from Case 1 (Table 1) showing thin media and wide lumen (adult pattern) (Verhoeff-van Gieson. $\times 500$ ).

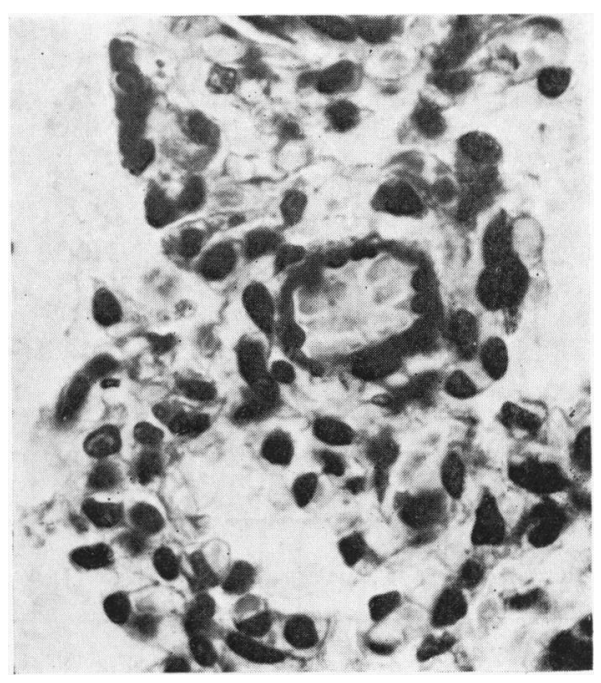

Fig. 4.-Arteriole from Case 2 (Table 1) showing thin wall, with practically no media and wide lumen (aduli pattern) (Verhoeff-van Gieson. $\times 500$ ). 
TABLE 1

LUMEN-TO-WALL RATIO OF SMALL PULMONARY MUSCULAR ARTERY AND ARTERIOLE IN 693 CASES

\begin{tabular}{|c|c|c|c|}
\hline $\begin{array}{l}\text { No. of } \\
\text { Cases }\end{array}$ & $\begin{array}{l}\text { Age in hours } \\
\text { and days }\end{array}$ & $\begin{array}{c}\text { Lumen-to-wall } \\
\text { Ratio of } \\
\text { Muscular Artery }\end{array}$ & $\begin{array}{c}\text { Lumen-to-wall } \\
\text { Ratio of } \\
\text { Arteriole }\end{array}$ \\
\hline $\begin{array}{r}90 \\
83 \\
108 \\
188 \\
101 \\
90 \\
33\end{array}$ & $\begin{array}{c}\text { Stillborn } \\
\text { Few min.-3 hr. } \\
3-12 \mathrm{hr} \text {. } \\
12-24 \mathrm{hr} \text {. } \\
24-48 \mathrm{hr} \text {. } \\
2-3 \text { days } \\
4-5 \text { days }\end{array}$ & $\begin{array}{r}1: 1 \\
1: 1 \\
1 \cdot 5: 1 \\
2: 1 \\
2 \cdot 5: 1 \\
3: 1 \\
3: 1\end{array}$ & $\begin{array}{r}1: 1 \\
1: 1 \\
1 \cdot 5: 1 \\
2: 1 \\
2 \cdot 5: 1 \\
3: 1 \\
3: 1\end{array}$ \\
\hline
\end{tabular}

Left ventricular dilatation was also observed grossly in all 7 cases: 4 of these had small patent ductus arteriosus as is usual in newborn infants, 2 had high ventricular septal defects and 1 had an atrial septal defect. Details of these are set out in Tables 2 and 3.

Of the 7 cases described above, 3 were premature infants and 4 were full term, all liveborn. All the 7 infants were born normally: 3 in hospital and 4 at home. From the available history all these infants appeared normal at birth and breathed normally. They developed respiratory distress at different periods, followed clinically by pulmonary oedema and cardiac failure. The cases born at home were brought to hospital because of respiratory distress. The maternal history in all these cases was noncontributory.

The necropsy findings were uniform: the heart showed left ventricular dilatation; the lungs were airless, rubbery and deep reddish pink; histological examination showed severe pulmonary oedema and an 'adult pattern' of pulmonary vessels which were engorged with red cells. This pulmonary vascular pattern was abnormal, as these infants were between a few hours to 3 days old.

\section{Discussion}

Normally, a change to the adult type of pulmonary vessel begins by the third month and is fully developed between 6 months and 1 year (Goodale and Thomas, 1954; Heath et al., 1958). The gradual
TABLE 2

LUMEN-TO-WALL RATIO OF SMALL MUSCULAR PULMONARY ARTERIES AND ARTERIOLES IN 4 CASES WITH 'ADULT PATTERN' ASSOCIATED WITH PATENT DUCTUS

\begin{tabular}{c|c|c|c|c|c|c}
\hline $\begin{array}{c}\text { Case } \\
\text { No. }\end{array}$ & $\begin{array}{c}\text { Age } \\
\text { (days) }\end{array}$ & Sex & $\begin{array}{c}\text { Lumen- } \\
\text { to-wall } \\
\text { Ratio of } \\
\text { Muscular } \\
\text { Artery }\end{array}$ & $\begin{array}{c}\text { Lumen- } \\
\text { to-wall } \\
\text { Ratio of } \\
\text { Arterioles }\end{array}$ & $\begin{array}{c}\text { Pulmonary } \\
\text { Oedema }\end{array}$ & $\begin{array}{c}\text { Left } \\
\text { Ventricular } \\
\text { Dilatation }\end{array}$ \\
\hline $\mathbf{1}$ & $\mathbf{1}$ & $\mathbf{F}$ & $\mathbf{7}: \mathbf{1}$ & $\mathbf{7}: 1$ & +++ & + \\
$\mathbf{2}$ & $\mathbf{2}$ & $\mathbf{F}$ & $\mathbf{7}: 1$ & $\mathbf{7}: 1$ & +++ & + \\
$\mathbf{4}$ & $\mathbf{3}$ & $\mathbf{F}$ & $\mathbf{8}: 1$ & $\mathbf{8}: 1$ & +++ & + \\
$\mathbf{M}$ & $\mathbf{8}: 1$ & $\mathbf{8}: 1$ & +++ & + \\
\hline
\end{tabular}

transition from the neonatal to the adult type is of vital importance, since a sudden and sharp fall in pulmonary vascular resistance would lead to flooding of the pulmonary vascular bed. This would be particularly dangerous if any communication existed between the two circulations at any level in the heart or great vessels, even if it be a simple small patent ductus frequently seen in newborn infants. With a rise in peripheral vascular resistance, a sharp fall in pulmonary vascular resistance would lead to a runoff of left ventricular blood into the lungs through any of these communications (Edwards, 1957). The pulmonary vascular bed immediately after birth cannot suddenly accommodate a large volume of blood coming from both ventricles. This is equally true of the left venticle, which cannot accommodate a large volume of blood and pump out enough to the systemic circulation; hence it fails, and this failure is of the high output type (Dammann and Ferencz, 1956b).

The respiratory distress and the cardiac failure in the above 7 cases are attributed to the sudden flooding of the pulmonary vascular bed. Complete relaxation of the pulmonary vessels had lowered the pulmonary vascular resistance to a great degree, and with the rising peripheral vascular resistance a leftto-right shunt had been established through the patent ductus, the interventricular septal defects and the interatrial septal defect, thus increasing the blood flow to the lungs. This had led to an increased volume of blood returning to the left heart leading to

TABLE 3

LUMEN-TO-WALL RATIO OF SMALL MUSCULAR PULMONARY ARTERIES AND ARTERIOLES IN 3 CASES WITH ADULT PATTERN AND VENTRICULAR OR ATRIAL SEPTAL DEFECT

\begin{tabular}{|c|c|c|c|c|c|c|c|}
\hline Case No. & Age (days) & Sex & Defect & $\begin{array}{c}\text { Lumen-to-wall } \\
\text { Ratio of } \\
\text { Muscular Artery }\end{array}$ & $\begin{array}{c}\text { Lumen-to-wall } \\
\text { Ratio of } \\
\text { Arterioles }\end{array}$ & $\begin{array}{c}\text { Pulmonary } \\
\text { Oedema }\end{array}$ & \begin{tabular}{l}
\multicolumn{1}{c}{ Left } \\
Ventricular \\
Dilatation
\end{tabular} \\
\hline $\begin{array}{l}5 \\
6 \\
7\end{array}$ & $\begin{array}{l}2 \\
2 \\
3\end{array}$ & $\begin{array}{c}\mathbf{M} \\
\mathbf{F}\end{array}$ & $\begin{array}{l}\text { V.S.D. } \\
\text { V.S.D. } \\
\text { A.S.D. }\end{array}$ & $\begin{array}{l}8: 1 \\
7: 1 \\
8: 1\end{array}$ & $\begin{array}{l}8: 1 \\
7: 1 \\
8: 1\end{array}$ & $\begin{array}{l}+++ \\
+++ \\
++t\end{array}$ & $\begin{array}{l}+ \\
+ \\
+\end{array}$ \\
\hline
\end{tabular}

V.S.D.-ventricular septal defects

A.S.D.-atrial septal defect 
overdistension of the left ventricle and left ventricular failure.

The only previous report of a similar condition was by Heath et al. (1958). Edwards (1957) mentions the possible dangers of a rapid fall in pulmonary resistance in an infant with ventricular septal defect. Dammann and Ferencz (1956b) mentioned this condition as one of the three possible courses the pulmonary vascular bed may take after birth. A review of the literature does not reveal any other reports of this condition.

Clinically it may bear a superficial resemblance to resorption atelectasis. Anatomically the two conditions are entirely different: in the 'adult pattern syndrome' there is dilatation of the muscular arteries and arterioles with fluid in the alveoli and no membrane, while in resorption atelectasis the vessels show only a foetal or neonatal pattern.

Thus, this premature dilatation of pulmonary vessels is a distinct clinico-pathological entity and should be thought of in newborn infants who are well immediately after birth and who later develop respiratory distress. The adult pattern of the pulmonary vessels in the newborn infant may also be one of the reasons why some children with patent ductus or septal defects die soon after birth while others, with identical defects, live longer. A small patent ductus in a newborn infant, which is considered to be of no significance becomes one of grave import when associated with an adult pattern of pulmonary vessels.

The aetiology of this condition is, as yet, obscure. This has been seen in mature and premature infants. The same factors, if any, which are responsible for retention of the foetal pattern in later years giving rise to primary hypertension may act in the reverse in these cases.

\section{Summary}

The pulmonary vasculature of 7 newborn infants out of a total of 700 cases studied showed an adult pattern. Of these, 4 were associated with patent ductus arteriosus, 2 with interventricular septal defects and 1 with interatrial septal defect. Clinically, these infants were normal at birth, but later developed respiratory distress followed by pulmonary oedema and cardiac failure. The premature dilatation of the pulmonary vessels is thought to be the cause of the respiratory distress and cardiac failure. The cause of this condition is, as yet, unknown.

I am grateful to Mr. V. Nalpon for the photomicrographs and to Mr. P. A. Samuel for helping with the manuscript, and to Professor K. Shanmugaratnam for helpful criticism.

\section{REFERENCES}

Barclay, A. E., Franklin, K. J. and Prichard, M. M. L. (1944). The Foetal Circulation and Cardiovascular System, and the Changes that they Undergo at Birth. Blackwell, Oxford.

Brenner, O. (1935). Pathology of the vessels of the pulmonary circulation. Arch. intern. Med., 56, 211.

Civin, W. H. and Edwards, J. E. (1951). The postnatal structural changes in the intrapulmonary arteries and arterioles. A.M.A. Arch. Path., 51, 192.

Dammann, J. F., Jr. and Ferencz, C. (1956a). The significance of the pulmonary vascular bed in congenital heart disease. I and II. Amer. Heart J., 52, 7.

(1956b). The significance of the pulmonary vascular bed in congenital cardiac disease. III. ibid., 52, 210.

and Muller, W. H., Jr. (1953). The role of the pulmonary vascular bed in congenital heart disease. Pediatrics, 12, 307.

Edwards, J. E. (1950). Structural changes of the pulmonary vascular bed and their functional significance in congenital cardiac disease. Proc. Inst. Med. Chic., 18, 134.

- (1957). Functional pathology of the pulmonary vascular tree in congenital cardiac disease. Circulation, 15, 164

- Douglas, J. M., Burchell, H. B. and Christensen, N. A. (1949). Pathology of the intrapulmonary arteries and arterioles in coarctation of the aorta associated with patent ductus arteriosus. Amer. Heart J., 38, 205.

Goodale, F., Jr. and Thomas, W. A. (1954). Primary pulmonary arterial disease. A.M.A. Arch. Path., 58, 568.

Heath, D., Swan, H. J. C., DuShane, J. W. and Edwards, J. E. (1958). The relation of medial thickness of small muscular pulmonary arteries to immediate postnatal survival in patients with ventricular septal defect or patent ductus arteriosus. Thorax, 13, 267.

Lind, J. and Wegelius, C. (1949). Angiocardiographic studies on the human foetal circulation. A preliminary report. Pediatrics, 4, 391. 